\title{
Investing in Couple Relationship Education in the UK: A Gender Perspective
}

\section{Liz van Acker}

School of Government and International Relations, Griffith University

E-mail: E.vanacker@griffith.edu.au

The UK Conservative-Liberal Democratic Coalition government has declared that marriage is imperative for society. This article examines couple relationship education (CRE), which aims to strengthen marriage and relationships. It argues that these programmes have potential because they offer opportunities for women and men to enhance their relationships through adult education that develops relationship skills and knowledge. For CRE to have a population level impact, however, knowledge of how to promote access to services designed for disadvantaged or vulnerable couples is critical. Gender disadvantage interacts with class, ethnicity, age and disability. Advocating marriage per se is too simplistic a solution to the complex problems of couples with diverse needs or low-income earners. If the government is serious about wanting to strengthen relationships and marriage, CRE would be a better investment if it was coordinated with policies and services such as balancing work and family and alleviating problems for low-income families.

Key words: Gender, marriage, couple relationship education.

\section{Introduction}

Relationship breakdown in heterosexual couples is prevalent in many societies across the Western world (EUROSTAT, 2012). The UK government has been considering how to encourage healthy family stability through early intervention programmes and how to remove the barriers to couple formation and marriage. There have been calls for restoring marriage at a time when citizens are experiencing multiple relationship transitions, including marriage and divorce, non-marital childbearing, cohabitation, lone parenthood and step-parenting. The cost of relationship breakdown has been calculated at approximately $£ 43.94$ billion per annum (Relationships Foundation, 2012). This incorporates direct expenditure on income support for lone parents and tax credits, housing, health and social care, civil and criminal justice and education.

This article examines couple relationship education (CRE) that endeavours to assist couples in sustaining healthy, mutually satisfying relationships, and to reduce relationship distress and separation. CRE is the provision of structured education about relationship knowledge, attitudes and skills (Halford et al., 2008: 497). Some people acquire these attributes through life experiences, but many people do not. These programmes can assist in preventing relationship issues from escalating into problems. Although the government tends to construct them as 'gender neutral', the fact is that these programmes operate within a gendered society. 
My argument is that without adequate political recognition of the disadvantage relating to issues such as gender and class by the UK government, the potential to address the relationship needs and concerns of women and men in both the public and private sphere is diminished. It is thus imperative that policies addressing matters such as the struggle to balance work and family and to achieve financial security are coordinated with marriage and relationship strengthening programmes. Studies have shown that couples who attend CRE are from middle-class, highly educated backgrounds (Coleman, 2012: 22). Knowledge of how to promote access to services designed for disadvantaged or vulnerable couples is therefore critical (Halford and van Acker, 2012). This includes people from different ethnic backgrounds, older people, couples where one or both are entering a second marriage or couples where one or both have a disability. Advocating marriage per se is too simplistic a solution to the complex problems of couples with diverse needs or low-income earners.

Robust relationships are linked to successfully balancing work and family, which in turn requires access to decent paying jobs, adequate child care and family friendly employment policies. Ideally, if CRE was coordinated with other policies such as public health, this may help to confront the gendered public/private division and tailor services to meet the needs of women and men. Spousal contentment and relationship stability are related to factors such as realistic expectations, commitment and emotional maturity, but also to adequate income and satisfaction with work and children (Walker et al., 2010). Investing in more relationship support so that couples with scarce resources can develop more satisfying relationships would require addressing associated problems such as child poverty, low education and poor housing. In this article, the first section sets the scene by covering the Coalition government and its policy environment. The second section examines the specifics of CRE and then considers its potential to address gender issues and related challenges concerning diversity.

\section{Government policies to strengthen marriage and couple relationships}

The Conservative-Liberal Democrat Coalition government tends to conflate stable couple relationships with stable families when attempting to develop relationship support. The challenge is to develop and implement a marriage and relationship policy that supports healthy, functional relationships. Stable families are not necessarily the answer, as they could be dysfunctional, even if enduring. For example, a woman who is subjected to domestic violence may be too scared to leave her marriage, but it would appear to the outside world that her relationship was 'stable'.

The Coalition government has revived policies to cultivate stable marriages and strengthen couple relationships as a legitimate area for policy intervention. Prime Minister David Cameron has supported the US's Healthy Marriage Initiative which the Bush Administration established in 2002, championing it as an important strategy for strengthening the family (Cameron, 2008). Mr Cameron treasures marriage and has pushed for a transferable tax allowance for married spouses (amid anger towards his proposal to abolish the child trust fund in 2010). The Work and Pensions Secretary, Ian Duncan Smith, demands tax breaks to end the 'bias' against married couples (Porter, 2011). Although the Liberal Democrats do not support the tax recommendation and are free to abstain from voting on the issue, the introduction of tax breaks is on the political agenda. The tax has been receiving much public attention, but there is a lack 
of evidence that a small tax concession would be a sufficient incentive to persuade people to get married if they would not otherwise (de Waal, 2008). Furthermore, any government-sanctioned tax incentives and benefits from marriage, almost by definition, impose economic penalties and reduce the welfare of families where parents are not married, have never married or are divorced. Yet, despite the disagreements surrounding the tax, the proposal sends a symbolic message highlighting the value government places on marriage.

The Coalition agreement promised to 'put funding for relationship support on a stable, long-term footing' and to encourage couples to 'use existing relationship support' (Cabinet Office, 2010: 20). Accordingly, the Coalition government announced support of $£ 30$ million over four years, funding service providers to deliver couple relationship programmes via the Department for Education. Evaluation of the various programmes was expected by late 2013. The findings of these randomised control trials (while not conclusive) will be critical in ascertaining whether any resulting pro-marriage landscape or evidence of stronger relationships would indicate that CRE would be a valuable use of public funds. If evaluations are positive, CRE could be expanded by working with existing service providers and infrastructure and would require a modest increase in funding.

The increased political and financial support for CRE provides a good start to strengthening gender relations. However, there have been few strategic efforts to connect the programmes to a wider network of services that could address challenges such as balancing family and work. In fact, the government is attempting to discharge governmental responsibilities onto individuals, communities and, most especially, to women and families. In a climate of increased austerity measures, there have been cuts to maternity payments, pregnancy and child benefits and services to women. Further, women make up 64 per cent of low paid workers, plus women will take on more caring roles as state services are withdrawn (Fawcett Society, 2013). Despite four decades of equal pay legislation, women were paid 79 per cent of male rates in 2010 (Allen, 2010). The number of unemployed women was at a sixteen-year high in early 2012 (Hall, 2012).

The following section examines CRE and its history, format, coverage and the organisations that offer them.

\section{Couple Relationship Education}

Healthy gender relations are imperative for sustaining strong, stable and satisfying relationships (McLanahan and Sandefur, 1994; Amato and Booth, 1997; Somerville, 2000). CRE is an important policy consideration because it provides opportunities to advance gender equalities and lessons about how women and men can articulate their needs and talk about their respective rights, their commitment to each other, how to raise their children and how to deal with emotions. CRE can be traced back to the 1940s when political support for what was then called 'marriage guidance' began. In 1949, the Home Office provided minimal funding to the Catholic Church and the Family Welfare Association and over the decades the emphasis on preparing for marriage and education for personal relationships increased (van Acker, 2008). CRE is designed to assist couples in communicating and dealing with problems before they worsen, thereby avoiding divorce and economic difficulties (Halford et al., 2008). It provides opportunities for partners to discuss and adopt more flexible attitudes toward their relationship and enhance its quality. 
CRE encompasses a range of different programmes and approaches: it is designed in different formats and can be delivered in a variety of settings. These include face-to-face classes which use an information-awareness approach, completing inventories which use an assessment approach with feedback or specific programmes such as Relationships Enhancement or the Premarital Relationship Enhancement programme which adopt skills training approaches (Halford and Snyder, 2012). Community sector organisations, such as Marriage Care, clergy, trained para-professionals, religious and lay leaders and teachers, deliver these services. Some providers charge a small fee (approximately $£ 90$ ) often based on an income scale. If couples do not want to participate in classes delivered via a Church, many programmes are delivered through relationship support services agencies, such as Relate or locally based community and family groups. Couples who wish to marry in the Catholic Church must undertake CRE, but otherwise the programmes are usually voluntary. Self-directed formats include books, DVDs, questionnaires, distance learning and online informational support and relationship programmes such as the range of online learning services offered by One Plus One. Research has calculated that 61 per cent of CRE is pre-marriage education and that approximately 24 per cent of all couples getting married receive some type of CRE (Clark et al., 2009: 51).

CRE addresses gender issues in different ways, offering strategies to tackle concerns such as the domestic labour and emotional support that women provide. It encompasses relationship knowledge by covering matters such as positive communication, managing conflict, balancing work and home and dealing with intimacy and sexuality. To improve relationship quality, programmes consider issues such as handling finances, sharing domestic chores and raising awareness about couple interactions and disagreements. CRE reflects on the role of romance and unrealistic expectations in couple relationships, offering a grounded analysis of people's experiences (van Acker, 2008). It is important to note that CRE is different from couple therapy, because it is intended for couples who are presently satisfied in their relationship and committed to it. It provides couples with insights about their attitudes, behaviours and expectations that can build on the strengths of their relationship and prevent the erosion of relationship satisfaction that many couples undergo (Halford and Snyder, 2012). Preventing relationship breakdown by strengthening a couple's relationship has profound benefits for adult and child well-being and for the parenting ability of the couple (Coleman and Glenn, 2009).

Evaluations of the long-term effects of CRE are lacking, but would be extremely useful. Although there are no longitudinal studies, there is evidence of the short-term effectiveness of skills training, in particular immediately after programmes (Hahlweg and Markman, 1988), and that improvements continue over time (Halford et al., 2010). At present, evidence from several studies has found that programmes of a few hours duration can improve communication skills and relationship quality, thereby strengthening relationships over a period of one to five years (Carroll and Doherty, 2003; Stanley et al., 2006, Hawkins et al., 2012). Benson's survey of 733 responses to marriage preparation from ten Community Trusts throughout the UK reported high satisfaction with the program: resolving conflict, general tips and getting to know each other better. Participants tended to be religious, and well educated with a high income (cited in Chang and Barrett, 2009: 37-38). Another study of marriage education delivered via the Catholic Church received positive evaluation (Coleman, 2012). Moreover, it has been suggested that regardless of the content of any specific curriculum, the act of participating in CRE with one's partner may in itself have a positive effect on commitment (Hawkins et al., 2012). 


\section{Marriage and gender inequalities}

Many feminists argue that marriage is a site of gendered power relationships that entails distinct gender roles buttressed by legal rules and sanctions. From a public policy viewpoint, the state has an interest in guaranteeing that people marry, procreate and take care of one another (Tronto, 2004: 38). In addition, it is in the state's interest to keep marriages intact and lessen the cost of divorce on the public purse. The state defines, confers and uses marital status as a way of protecting and supporting intimate caregivers (families) in ways which place the burden on women.

Although marriage has been a symbol of women's oppression, it is not a historically fixed institution: gender relations have changed. Couples now bring emotional expectations to marriage based on love and the ideal of lifelong monogamy and intimacy (Coontz, 2005). Marriage has steadily become fairer, more fulfilling and more effective in fostering the well-being of both adults and children, but it has also become more optional and more fragile (Coontz, 2005: 301). Many women marry for emotional reasons, based on personal choice and romantic expectations (van Acker, 2008). As Grymes (1996) puts it,

Whatever we may have accomplished in legislation, the gap between women's and men's understanding of relationships, marriage and home life has remained wide. For many women, relationships are the centre of our universe, often to a fault. We tend to subordinate ourselves and our work to our relationships. (1996: 23)

The allure of marriage remains not only because it 'continues to be identified with the emotional security of regular companionship', but because marriage offers 'promises of romance and intimacy' (Shumway, 2003: 229). The emotional life of marriage is linked to the myth of 'living happily ever after', which is a significant factor in modern cultures and relationships for both women and men. However, the increased expectations of romantic love can lead to more vulnerable relationships and disappointment (Somerville, 2000). Giddens argues that marriage has become 'just one life-style among others' (1992: 154), as more couples choose a 'pure relationship' which is entered into for its own sake, based on sexual and emotional equality. However, Giddens does not consider gender inequalities in relationships or within the domestic sphere. The assumption that two people in a couple are equal and autonomous, can articulate their needs and talk about their respective rights and obligations is questionable, given that an estimated 45 per cent of marriages end in divorce.

Gender inequality continues to be one of the main barriers to satisfying heterosexual relationships. While marriage laws are gender-neutral, cultural norms and employment practices perpetuate a division of labour at work and at home that result in a system of gender hierarchy (O'Connor et al., 1999; Shanley, 2004). A well-known problem is that marriage tends to reproduce and solidify a gendered division of labour and norms of dependency. Overall, wives support their husbands in ways that offer women fewer benefits than men. Women take responsibility for their family's emotional intimacy. Consequently, the division between workers and caregivers makes it less likely that men will develop interpersonal and caregiving skills (Shanley, 2004). Women's domestic labour is unpaid, unmonitored and not reciprocal (Marso, 2010). Women still do the 'double' or 'second shift' (Hochchild and Machung, 1990), performing housework and retaining primary responsibility for child care and other family members, even if 
they are the principal bread winner (Somerville, 2000; Cooke and Baxter, 2010; Kan, 2012).

The gender division of labour is very slowly breaking down: men's contribution to domestic work increased from ninety minutes per day in the 1960s to 148 minutes per day in the early 2000s (Kan et al., 2011: 236-7). Nevertheless, 2009-10 data from Understanding Society showed that amongst married couples of working age women carry out approximately 15.4 hours of housework (excluding childcare) per week while men carry out an average of 5.8 hours (cited in Kan, 2012). Further studies have shown that the division of labour within the home is a significant source of marital distress. Each partner's perception of fairness (rather than the actual amount of time that they contribute to household chores and childcare) is linked to marital quality (Chang and Barrett, 2009).

Different wage earning capacities give men more material resources and this in turn affects dynamics within the family. In 2012, full-time earnings for men were $£ 546$ per week compared to $£ 449$ per week for women. The gender pay gap continued, but decreased slightly from 10.5 per cent in 2011 to 9.6 per cent in 2012 (ONS, 2012a). A husband's legal and economic authority over his wife has diminished, but people have 'inherited unconscious habits and emotional expectations that perpetuate female disadvantage in marriage' (Coontz, 2005: 311). Moreover, women may pay a significant 'motherhood penalty' for having children. An analysis of cohort studies by the Institute for Public Policy Research (IPPR) found that women born in 1958 who had their first child between the ages of twenty-five and thirty-two were likely to earn 12 per cent less than women without children. For women born in 1970 who had children at the same age, this difference was approximately 10 per cent. If women born in 1958 had their first child between the ages of eighteen and twenty-four, they were likely to earn 17 per cent less than a woman without children. Those born in 1970 who had children at the same age were likely to earn 20 per cent less than women without children (IPPR, 2013: 15). Wives who do not participate in the paid workforce may be financially dependent on their husbands, thereby generating women's vulnerability within their marriage and reducing their ability to leave unsatisfactory relationships (Chang and Barrett, 2009). Nevertheless, men may also be vulnerable. Men tend to work longer hours: 18 per cent work more than 50 hours per week, compared to six per cent of women (OECD, 2013). Consequently, many men have a poor work-life balance, which causes stress in their relationships. Because men are usually the main income earner in male/female households that are raising children, there is more pressure on them with the threat or reality of unemployment (Wilkins, 2013).

It is as unreasonable to condemn matrimony as it is to suggest it as a panacea for the social ills in contemporary society (which some politicians have done, particularly in the wake of the 2011 riots). Acknowledging that wedlock does not necessarily provide solutions would move beyond allegations about the demise of personal responsibility, parental authority and family values. This is not to suggest that people want to abandon marriage. Various studies indicate that the aspiration to marry is still high among young people (North, cited in Relate, 2011) and this applies across the social and economic spectrum (Callan, 2008). Given these aspirations, it seems sensible for policy makers to provide support to encourage satisfying couple relationships. Accordingly, it is important to increase awareness about gender issues in marriage such as romantic expectations, the emotional and domestic division of labour and financial security mentioned above. The next section demonstrates the challenges in addressing these gender concerns when considering the potential of CRE. 


\section{Challenges concerning gender and CRE}

It has been difficult for governments to support CRE for a number of reasons concerning the policy constellation and dilemmas of policy that support gender relations. Intervening in the personal sphere of partner relationships, confronting the needs of low-income earners and disadvantaged couples and addressing the lack of awareness about, and participation in, CRE are just some of the obstacles that governments will encounter if they are intent on making CRE programmes as effective as possible.

\section{The personal sphere of partner relationships}

Controversial debates about the 'proper' role of governments in managing, promoting or altering the boundaries around marriage and couples have flourished (Clulow, 2005; Butler and Margo, 2007; Morgan, 2007; de Waal, 2008, Centre for Social Justice, 2010). Couple relationships are commonly believed to be an intimate and personal matter and 'none of the government's business' (van Acker, 2008). Although the Conservative Party has consistently advocated and praised marriage, the previous Labour government retreated from strong support for marriage in the early 2000s as it became reluctant to intervene in personal relationship matters. The elimination of child poverty and not excluding or penalising single mothers were issues for the Labour Party (van Acker, 2008). Government support for CRE was condemned for promoting a nanny state and being paternalistic. Politicians were accused of social engineering and telling people what to do (McLanahan et al., 2005). Governments therefore face a policy dilemma because they wish to avoid accusations that they are 'preaching' to their citizens, but the success or demise of people's personal relationships is related to relationship problems including low living standards, health care, unemployment and demands for welfare support.

\section{Confronting the needs of low-income earners and disadvantaged couples}

Governments may wish to increase marriage rates, however marriage has changed in terms of its trends and who gets married. First, marriage may be a consequence rather than a cause of stable relationships. Successful marriage can be partially explained by self-selection, that is men and women who choose to marry in the first place are more likely than unmarried couples to be better adapted and have better relationships (Cowan and Cowan, 2005). They are also likely to have steady employment, higher education and higher wages. While marriage does not actually cause these differences, couples who are financially well-off are more likely to marry and to remain married (Smock, 2004). Analysis of data from the Millennium Cohort Study comparing cohabitation and marriage to ascertain which led to more relationship stability found that while cohabiting parents are more likely to separate than married ones, 'different sorts of people choose to get married and have children' (Goodman and Greaves, 2010). Moreover, children whose parents were married achieved better cognitive and social outcomes, on average, than children born into other family types. Relationship stability in this study can be explained by higher levels of education and higher socio-economic status. Other explanatory factors included some aspects of family structure, for example if the mother was young or whether her pregnancy was planned (Goodman and Greaves, 2010). It may be the selection effect 
rather than marriage per se that has a direct bearing on relationship stability and outcomes for children.

The government wants people to get married, but couples may avoid marriage because they are fearful that they cannot meet its high expectations. Couples are unwilling to make the commitment and are not confident that marriages last forever (Walker et al., 2010). Opting for cohabitation requires a private commitment that is not as difficult to break and avoids the potential distress of divorce. Furthermore, many cohabiting couples do not wish to pay for a wedding (McGinnis, 2003). The cost of an average wedding in 2013 was more than $£ 16,000$ (UK Wedding and Belles, 2013).

Marriage has increasingly become a 'luxury item' or an indicator of prestige and status (Cherlin, 2004). Before they wed, individuals wish to achieve certain life markers first, such as establishing a successful career, robust finances, travelling and experiencing different lifestyles. Couples are unlikely to choose matrimony if they are unable to afford or access the milestones such as completing their education and buying a house. Marriage therefore has become an unattainable goal for many lower-income, low-educated couples who want secure employment, good housing and future prospects before considering wedding plans (Walker et al., 2010). Less educated women are more likely to cohabit, raise children out of wedlock and experience the dissolution of their relationships (Holmes and Kiernan, 2010). This is connected to wider problems such as inadequate access to health, education, employment, social support and housing (Hansen et al., 2010). Lower status work and lower income levels are linked to higher divorce, and divorce is more likely when the husband is unemployed or has erratic employment (Kiernan and Mueller, 1998). Financial pressures can cause stress and conflict in marriages and relationships (Glenn and Coleman, 2009; Joseph and Rowlingson, 2011). Consequently, family instability and poverty can mutually reinforce one another. If couples on low incomes do marry, this will not magically raise their family out of poverty if their circumstances are difficult, for instance when they have few skills, no jobs, and poor housing. Further, some individuals may be struggling with depression, substance abuse or domestic violence, and have inadequate resources to deal with their problems.

Governments have not adequately coordinated the delivery of programmes that would offer low-income couples the opportunity to strengthen their personal relationships with policies that balance gender, family and work commitments. Yet couples who are poor face greater risks of relationship breakdown. If their relationship does end, they are likely to experience more poverty (Kiernan et al., 2004). Exacerbated by recent policies, one of the fastest growing demographic groups in the UK is the working poor family, including one or two parents who are in the labour market, but whose wages are insufficient to raise their family above the poverty threshold. Low-income mothers are being encouraged to move into paid work, but they cannot cover the high cost of childcare (Fawcett Society, 2013). There have been discussions about tax relief for childcare costs, particularly for the working poor with young children, but they have not been finalised (Wintour, 2013). Greater paternity leave and support for fathers would also help (Stanley and Williams, 2005).

As Hughes and Cooke succinctly express it, 'poverty is a cause of fractured families as well as being its consequence' (2007: 250). In the aftermath of the global financial crisis, women in low-income work or lone mothers bore the brunt of government policies and calls for severe cuts to public spending (Institute for Public Policy Research, 2009). Of course, a range of policies and programmes target poor families. The Social Justice 
Outcomes Framework (HM Government, 2012) presents the government's vision where different services collaborate to tackle the cause of poverty. The goal is to shape future policy by highlighting priorities and identifying progress as well as areas where more attention is necessary. A crucial aspect is supporting families, family stability and the quality of parental relationships. The framework acknowledges the importance of the presence of the same two parents in a warm, stable relationship throughout childhood' (HM Government, 2012: 8). In its goal of delivering social justice, the framework highlights the need to support young people and the most disadvantaged adults and emphasises the value of work. But it does not include other measures such as assessing well-being outcomes for these groups or acknowledging the relevance of conflict and communication and mental health for couple relationships or children. Moreover, marriage policies such as CRE cannot work if men are chronically unemployed, in prison, on drugs, abusive or depressed (Carbone and Cahn, 2012: 25). Addressing economic hardship and improving social services is imperative, but neglecting the couple relationship which is at the heart of the family is not the answer: a multi-dimensional strategy that incorporates diverse needs, including gender, is essential to develop and implement effective programmes.

Couples who have little resilience in their personal relationship during difficult times confront many challenges. Low-income families continue to endure more than their share of inadequate access to education, health, housing, job opportunities, child support or paid parental leave, thereby feeling the strains on their relationships (Fawcett Society, 2013). If conflict occurs as a result of economic and social pressures, and partners do not support each other, this leads to weaker relationships (Glenn and Coleman, 2009).

Marriage is not a remedy that can replace the government's obligations towards poor, lone mothers and fathers. However, a major repercussion of divorce or relationship breakdown is that it hits women disproportionately. The income of women with children decreases by 12 per cent, while that of their partners increases by about 30 per cent on separation (Jenkins, 2008). Because society often assumes that mothers 'should' bear primary responsibility for the care of children, women are more likely to become the main carers when relationships break down, therefore becoming lone parents. In 2011, there were nearly 2 million lone parents with dependent children: women accounted for 92 per cent of lone parents and men for 8 per cent. These percentages have been consistent since 2001 (ONS, 2012b). Half of all lone parents live in poverty and experience declining living standards (Jenkins, 2008). The median gross weekly pay for male single parents is $£ 346$, while for female single parents it is $£ 194.40$ (Fawcett Society, 2013).

\section{Increasing awareness of and participation in CRE}

Apart from the above economic problems, a service delivery challenge related to the government's current CRE measures is the lack of public awareness about the programmes. There is little knowledge and insufficient funding for advertising and publicising the available services. People who could benefit from the programmes may be unaware that they exist or that they would be useful. At a broader level, there are gaps in the delivery of CRE: programmes are not easy to find, access or understand and are offered by organisations that do not have secure funding to be able to monitor the services that they provide (Chang and Barrett, 2009: 97). A Department of Children, Schools and Families study noted that couples spoke very positively about the value of CRE because 
it encouraged them to think and discuss issues which they may not have otherwise considered (Walker et al., 2010: 70). This finding reinforces the various evaluative studies mentioned above which demonstrate the soundness of CRE. Programmes could be advertised at health clinics, Sure Start centres, women's centres, men's groups and register offices to raise awareness and to encourage more participation. By normalising CRE, it could become as acceptable to attend as it is to attend antenatal or parenting classes.

A related policy challenge in implementing CRE is changing people's attitudes so that it becomes more acceptable to participate in the programmes. Attitudinal barriers to attending relationship programmes include the belief that adults 'naturally' know how to be good partners and do not need any measures such as relationship teaching to develop skills (Chang and Barrett, 2009: 44). Men in particular appear reluctant to seek and participate in relationship support programmes, and have little understanding about what support is available (Anderson et al., 2009; Chang and Barrett, 2009; Gelatt et al., 2010). Men are more likely than women to regard these services as for people with very serious problems and are less likely to feel comfortable talking to any therapist or counsellor (Anderson et al., 2009). Women are more willing to discuss their personal relationships and accept that they might benefit from support (Chang and Barrett, 2009). A recent report by the Men's Health Forum in conjunction with Relate recommends that the Department for Education should pilot a campaign to encourage men to engage in relationship support and to improve and increase the access points to these services (Wilkins, 2013). If the government is to spend its investment effectively, it needs to address the resistance or stigma attached to participating in programmes such as CRE.

\section{Conclusions}

The current UK government values marriage. It has not, however, acknowledged that marriage continues to be a gendered institution and confronts numerous obstacles, tensions and contradictions. In response to the growing political concern about strengthening marriage and couple relationships, the government has endorsed programmes such as CRE. These programmes, while not a panacea for gender inequalities, offer potential to address gender concerns so that men and women can improve communication, learn problem-solving skills and manage conflicts and enhance the quality of their relationships. This article, however, has demonstrated that CRE for the 'well-to-do' is not enough and that it should be more easily available for those on low incomes: flourishing relationships do not develop in a policy vacuum. It has argued that public investment is required not only in adult education programmes that provide relationship knowledge and skills, but in recognising disadvantage for diverse groups and alleviating stressful areas of daily life such as juggling work and family, employment opportunities and family friendly work environments. Government contributions at the macro level can assist with addressing the problems and pressures confronted by families and which affect their marital relationships, while CRE can help with relationship knowledge and quality at the micro level.

Although these programmes offer couples assistance with developing their personal skills, in isolation CRE is unlikely to appreciably affect the well-being of disadvantaged women and men and their children. The decline in policy support for women demonstrates the low priority given to gender concerns and needs, even though this support could actually contribute to stronger couple relationships. Government cutbacks, as well as low 
pay and high unemployment, will add to financial anxiety and relationship pressures, thereby detracting from any benefits from CRE. Assuming a neutral role for the individuals within marriage will do little to heed women's demands for domestic and economic equality. Policies have not explicitly acknowledged the implications of couples' high expectations of relationships or that domestic labour persists as a burden for women.

While it is crucial to acknowledge the financial constraints that the UK government is facing, expanding the availability of CRE does not have to be an expensive investment. Programmes can be delivered with a small increase in funding for service providers. The success of CRE depends on increasing people's accessibility to services, raising awareness and motivating couples, especially men, to participate. Evaluations of the effectiveness of the programmes, not just in the short-term, would also be useful.

Overall, programmes to strengthen relationships should be positioned within a gendered context that considers both the public and the private spheres. A clear, coherent strategy combining couple relationship support and 'gender-friendly' policies is surely feasible and desirable for strengthening all families, not just the wealthy.

\section{Acknowledgement}

I would like to thank the Centre for Governance and Public Policy at Griffith University for its ongoing support.

\section{References}

Allen, K. (2010) 'Equal pay for women not likely till 2067, says research', The Guardian, 19 August.

Amato, P. and Booth, A. (1997) A Generation at Risk: Growing Up in an Era of Family Upheaval, Cambridge, MA: Harvard University Press.

Anderson, S., Brownlie, J. and Given, L. (2009) 'Therapy culture? Attitudes towards emotional support in Britain', The British Attitudes Survey, London: Sage.

Butler, D. and Margo, J. (2007) 'Freedom's orphans: raising youth in a changing world', in N. Pearce and J. Margo (eds.), Politics for a New Generation, Basingstoke: Palgrave Macmillan.

Cabinet Office (2010) The Coalition: Our Programme for Government, London: Cabinet Office.

Callan, S. (2008) Breakthrough New Zealand?, Auckland: Maxim Institute, http://groups.yahoo.com/ group/rationshed/message/1508\#story0.

Cameron, D. (2008) 'Stronger families', Speech to Relate Institute, 9 June.

Carbone, J. and Cahn, N. (2012) 'Red v. blue marriage', in M. Garrison and E. Scott (eds.), Marriage at the Crossroads: Law, Policy, and the Brave New World of Twenty-first-century Families, Cambridge: Cambridge University Press.

Carroll, J. and Doherty, W. (2003) 'Evaluating the effectiveness of premarital prevention programs: a meta-analytic review of outcome research', Family Relations, 52, 2, 105-18.

Centre for Social Justice (2010) Green Paper on the Family, London: Centre for Social Justice.

Chang, Y. and Barrett, H. (2009) Couple Relationships: A Review of the Nature and Effectiveness of Support Services, London: Family and Parenting Institute, London.

Cherlin, A. (2004) 'The deinstitutionalization of American marriage', Journal of Marriage and Family, 66, 4, 848-61.

Clark, M., Lynas, R. and Percival, D. (2009) Building Strong Foundations: The Case for Couple Relationship Education, Cambridge: Relationships Foundation.

Clulow, C. (2005) 'Couples and parenting: missing the links?', Sexual and Relationship Therapy, 20, 3, $265-7$.

Coleman, L. (2012) Marriage Preparation in the Catholic Community: An Independent Assessment of Evaluation Data, London: One Plus One. 
Coleman, L. and Glenn, F. (2009) When Couples Part: Understanding the Consequences for Adults and Children, London: One Plus One.

Cooke, L. and Baxter, J. (2010) "Families" in international context: comparing institutional effects across western societies', Journal of Marriage and Families, 72, 3, 516-36.

Coontz, S. (2005) Marriage, A History: From Obedience to Intimacy or How Love Conquered Marriage, New York: Viking.

Cowan, C. P. and Cowan, P. A. (2005) 'Two central roles for couples relationships: breaking negative intergenerational patterns and enhancing children's adaptation', Sexual and Relationship Therapy, 20, 3, 275-88.

de Waal, A. (2008) Second Thoughts on the Family, London: Civitas.

EUROSTAT (2012) 'Marriages per 1,000 persons data table', http://epp.eurostat.ec.europa.eu/tgm/table.do? tab $=$ table \&plugin $=1$ \&language $=$ en \&pcode $=$ tps 00012 .

Fawcett Society (2013) Equal Pay: The Facts, London: The Fawcett Society.

Gelatt, V., Adler-Baeder, F. and Seeley, J. (2010) 'An interactive web-based programme for stepfamilies: development and evaluation of efficacy', Family Relations, 59, 5, 572-86.

Giddens, A. (1992) The Transformation of Intimacy: Sexuality, Love and Eroticism in Modern Society, Cambridge: Polity Press.

Glenn, F. and Coleman, L. (2009) Relationships and the Recession, iCOR - the online Information Centre on Relationships, London: One Plus One.

Goodman, A. and Greaves, E. (2010) Cohabitation, Marriage and Relationship Stability, London: Economic and Social Research Council, Institute for Fiscal Studies.

Grymes, P. (1996) The Romantic Trap, Kerry, Ireland: Brandon.

Hahlweg, K. and Markman, H. (1988) 'Effectiveness of behavioural marital therapy: empirical status of behavioural techniques in preventing and alleviating marital distress', Journal of Consulting and Clinical Psychology, 56, 3, 440-7.

Halford, W. K. and Snyder, D. K. (2012) 'Universal processes and common factors in couple therapy and relationship education', Behaviour Therapy, 43, 1, 1-12.

Halford, W. K. and van Acker, E. (2012) 'Are governments and marriage strange bedfellows?', in P. Noller and G. Karantzas (eds.), The Wiley-Blackwell Handbook of Couples and Family Relationships, London: Wiley-Blackwell.

Halford, W. K., Markman, H. J. and Stanley, S. M. (2008) 'Strengthening couple relationships with education: social policy and public health perspectives', Journal of Family Psychology, 22, 4, 497505.

Halford, W. K., Wilson, K., Watson, B., Verner, T., Larson, J., Busby, D. and Holman, T. (2010) 'Couple relationship education at home: does skill training enhance relationship assessment and feedback?', Journal of Family Psychology, 24, 2, 188-96.

Hall, J. (2012) 'Unemployment at 17-year high', The Independent, 15 February 2012.

Hansen, K., Joshi, H. and Dex, S. (eds.) (2010) Children of the 21st Century: The First Five Years, Bristol: Polity Press.

Hawkins, A., Stanley, S., Blanchard, V. and Albright, M. (2012) 'Exploring programmatic moderators of the effectiveness of marriage and relationship education programmes: a meta-analytic study', Behaviour Therapy, 43, 1, 77-87.

HM Government (2012) Social Justice Outcomes Framework, London: HM Government.

Hochchild, A. and Machung, A. (1990) The Second Shift, New York: Avon Books.

Holmes, J. and Kiernan, K. (2010) Fragile Families in the UK: Evidence from the Millennium Cohort Study, York: University of York, http://www.york.ac.uk/media/spsw/documents/research-andpublications/HolmesKiernan2010FragileFamiliesInTheUKMillenniumCohort.pdf (accessed 14 March 2012).

Hughes, B. and Cooke, G. (2007) 'Children, parenting and families: renewing the progressive story', in N. Pearce and J. Margo (eds.), Politics for a New Generation, Basingstoke: Palgrave Macmillan.

Institute for Public Policy Research (2009) When Times are Tough: Four Families'Stories, London: IPPR. 
Institute for Public Policy Research (2013) Great Expectations: Exploring the Promises of Gender Equality, IPPR: London.

Jenkins, S. (2008) Marital Splits and Income Changes over the Longer Term, Colchester: University of Essex, Institute for Social and Economic Research.

Joseph, R. and Rowlingson, K. (2011) 'Her house, his pension? The division of assets among (ex-)couples and the role of policy', Social Policy and Society, 11, 1, 69-80.

Kan, M., Sullivan, O. and Gershuny, J. (2011) 'Gender convergence in domestic work: discerning the effects of interactional and institutional barriers from large-scale data', Sociology, 45, 2, 23451.

Kan, M. (2012) 'Revisiting the "doing gender" hypothesis - housework hours of husbands and wives in the UK', in S. McFall (ed.), Understanding Society: Findings 2012, Colchester: University of Essex, Institute for Social and Economic Research.

Kiernan, K. and Mueller, G. (1998) The Divorced and Who Divorces?, CASE Paper 7, London: CASE, http://sticend.Ise.ac.uk/dps/case/cp/paper7.pdf.

Kiernan, K., Land, H. and Lewis, J. (2004) Lone Motherhood in the Twentieth Century: From Footnote to Front Page, Oxford: Clarendon Press.

Marso, L. (2010) 'Marriage and bourgeois respectability', Politics and Gender, 6, 1, 145-53.

McGinnis, S. (2003) 'Cohabiting, dating and perceived costs of marriage: a model of marriage entry', Journal of Marriage and Family, 65, 1, 105-16.

McLanahan, S. and Sandefur, G. (1994) 'Growing Up With a Single Parent: What Hurts, What Helps', Cambridge, MA: Harvard University Press.

McLanahan, S., Donahue, E. and Haskins, R. (2005) 'Introducing the issue', The Future of Children, 15, 2, 3-12.

Morgan, P. (2007) The War Between the State and the Family: How Government Divides and Impoverishes, London: Institute of Economic Affairs.

O'Connor, J., Orloff, A. and Shaver, S. (1999) States, Markets, Families, Gender, Liberalism and Social Policy in Australia, Canada, Great Britain and the United States, Cambridge: Cambridge University Press.

Office for National Statistics (2012a) 'Annual survey of hours and earnings, 2012: provisional results', Statistical Bulletin, Newport: Office for National Statistics.

Office for National Statistics (2012b) Lone Parents with Dependent Children, Newport: Office for National Statistics. Organisation of Economic and Cooperative Development (2013) Better Life Index, Paris: OECD, http://www.oecdbetterlifeindex.org/countries/united-kingdom/.

Porter, A. (2011) 'Tax breaks for married couples, IDS insists "We must end bias against marriage"', The Telegraph, 2 October, http://www.telegraph.co.uk/news/politics/conservative/8803013/Tax-breaksfor-married-couples-IDS-insists-We-must-end-bias-against-marriage.html.

Relate (2011) 'Rate of marriages continues to fall', press release, 30 March, Relate, London, http://www.relate.org.uk/press/36/index.html (accessed 5 September 2013).

Relationships Foundation (2012) Counting the Cost of Family Failure: 2011 Update, Cambridge: Relationships Foundation.

Shanley, M. (2004) 'Just marriage: on the public importance of private unions', in M. Shanley (ed.), Just Marriage, New York: Oxford University Press.

Shumway, D. (2003) Modern Love: Romance, Intimacy and the Marriage Crisis, New York: New York University Press.

Smock, P. (2004) 'The wax and wane of marriage: prospects for marriage in the 21st century', Journal of Marriage and Family, 66, 4, 966-73.

Somerville, J. (2000) Feminism and the Family: Politics and Society in the UK and USA, Basingstoke: Macmillan.

Stanley, K. and Williams, F. (2005) 'Relationships between parents', in K. Stanley (ed.), Daddy Dearest?: Active Fatherhood and Public Policy, London: Institute for Public Policy Research. 
Stanley, S., Amato, P., Johnson, C. and Markman, H. (2006) 'Premarital education, marital quality, and marital stability: findings from a large, random, household survey', Journal of Family Psychology, 20, $1,117-26$.

Tronto, J. (2004) 'Marriage: love or care?', in M. Shanley (ed.), Just Marriage, New York: Oxford University Press.

van Acker, E. (2008) Governments and Marriage Education Policy: Perspectives from the UK, Australia and the US, Basingstoke: Palgrave Macmillan.

UK Wedding and Belles (2013) 'Average wedding costs 2013', http://www.ukwedding belles. com/ weddingmagazine/budgeting.

Walker, J., Barrett, H., Wilson, G. and Chang, Y. (2010) Relationships Matter: Understanding the Needs of Adults (Particularly Parents) Regarding Relationship Support, Newcastle University: Institute of Health and Society.

Wilkins, D. (2013) Try to See it My Way: Improving Relationship Support for Men, London: Men's Health Forum and Relate, http://www.relate.org.uk/userfiles/documents/MensReportWEB.pdf

Wintour, P. (2013) 'Nick Clegg promises to "fill the gap" left by childcare support cuts', The Guardian, 10 January. 